\title{
Knowledge and Public Awareness of Cancer Risk Factors and Determinants among Yemeni adults- A Community Based Cross-Sectional Study
}

\author{
Amran Ibrahim ${ }^{1,2,3, ~ *, ~ K a r i m a ~ E l ~ R h a z i ~}{ }^{1}$, Bouchra Benazzouz ${ }^{2}$ and Sawson Mohammed ${ }^{3}$ \\ ${ }^{1}$ Department of Epidemiology and Public Health, Sidi Mohamed Ben Abdullah University, Faculty of Medicine and Pharmacy of \\ Fez, B.P 1893, Route Sidi Harazem, Km 2.2, Fez, Morocco \\ 2 Department of Biology, Laboratory of Biology and Health, Faculty of Sciences, Ibn Tofail University, Kénitra, Morocco \\ ${ }^{3}$ Environmental Sciences and Biological Research Authority, Al-Hudaydah, Yemen \\ ${ }^{4}$ Faculty of Medicine and Health Sciences Aden University. Yemen
}

\begin{abstract}
Cancer is the second biggest cause of premature death after cardiovascular diseases. However, the majority of cancers are caused by risk factors that may be changed. Knowledge is frequently a component of the behavior modification process. Data on the target population's level of knowledge is required. A cross-sectional survey about nine risk factors for cancer was conducted in four areas in Yemen. The data was analyzed using spss statistics (version20). Among the (571) subjects who took part in the research. The majority of respondents agreed that active smoking, alcohol consumptions are cancer risk factors and physical activity as a preventive factor for developing cancer. However, fewer respondents agreed that passive smoking, lack of fresh vegetables and fruits, sun overexposure, obesity, air pollution in cities and indoor smoke, physical inactivity are cancer risk factors. Participants' responses were shown to have a strong relationship with their educational level, residency, and gender. The higher the educational level and whenever the gender was male and residency urban the higher the probability that respondents identified cancer risk factors including smoking and physical activity as a preventive factor $(p<0.0005)$. The findings show that this community has little knowledge of prevalent cancer risk factors.
\end{abstract}

Keywords: Awareness, Determinants, Cancer, Risk factors, Yemen

\section{Introduction}

Based on the most recently available World Health Organization (WHO) data, the world over, the impact of cancer in terms of incidence and mortality is second just after cardiovascular diseases. The estimated number of new cases each year is expected to rise from 11 million in 2002 to 27 million by 2030 of which approximately $60 \%$ (about 6.5 million) of all new cases are expected to occur in developing, so cancer in developing countries is a growing and soon to be a major problem, mainly due to a growing and aging population. According to the American Cancer Society, this number will rise to 27 million cases by 2050 . [1,2].
Several scientific researchers from different countries of the world have focused on the importance of increasing public awareness and general societal knowledge of the warning signs and symptoms of cancer. Scientific evidence indicates that a large part of the increase in the incidence of cancer is due to many factors, including poor awareness of cancer signs and symptoms and risk factors. Poor availability of tests or early screening programs and limited access to standard treatment or not available in some developing countries $[3,4]$. Some studies showed that increase a population's basic cancer knowledge is as important for controlling cancer as are diagnostic tools, early screening programs, and new preventive approaches [5]. However, studies examining public awareness about the warning signs of cancer 
concerning early detection and prevention in various countries have reported that general public knowledge is poor [6]. It is estimated that more than half of all cancer cases are caused by a variety of unhealthy risk factors. [7]. Indeed, because most cancer risk factors are avoidable and adjustable, the majority of cancer cases can be avoided. [8-10]. These involve smoking, nutritional deficiencies, excessive alcohol consumption, sedentary lifestyles, excessive sun exposure, sexually transmitted infections, and obesity [7-11]. Therefore, determine the knowledge and general awareness of Yemenis about cancer is the major purpose of this study. Yemen is one of the developing countries in the Middle East located on the south tip of the Arabian Peninsula. Based on World meter elaboration of the latest United Nations data the current population of Yemen is approximately $(30,313,246)$, with $(50.09 \%)$ males and (49.91\%) females, distributed by $(70.1 \%)$ in the rural areas and $(29.9 \%)$ in urban areas. Yemen is one of the poorest countries in the Middle East, it ranked as the 160th country (of 188) based on the Human Development Index in 2014, It is estimated that $35 \%$ of its population was living below the national poverty line in 2015 and almost half of the population lacks access to sufficient and nutritious food [12]. In Yemen, cancer is a major public health problem [13]. The known underlying risk factors and the size of the problem are not yet well studied and enough. The most common cancers in Yemen are breast cancer, NHL (Non-
Hodgkin's lymphoma) cancer, Leukemia Stomach cancer, ovary cancer [14]. The total number of registered cancer cases by the Ministry of Health was approximately between 20000 to 25,000 cases of different cancers until 2018. However, the true cancer incidence in Yemen is unknown due to limited resources for pathology, the scarcity of epidemiological studies and the scarcity, and quality of medical records, and limited epidemiology resources [15]. Moreover, there are no early screening programs for most cancers, except for breast cancer which was introduced in 2005 (The National Cancer Control Foundation (NCCF)). There are also popular religiosity and other Cultural, social barriers that might contribute to the delay in the early detection and diagnosis of cancer. Primary prevention has been identified as playing a major role in the lessening of cancer incidence rates (prevention is better than cure) [16]. For that, knowledge of cancer risk factors can play a key role in avoiding these factors, thus reducing mortality. A common classic example of this is the proven link between lung cancer and smoking that offers the best chance of preventing lung cancer [17]. As far as we know, there has been no previous study conducted in Yemen to identify public awareness of risk factors for cancer. Therefore, the study aims to recognize the level of public awareness of risk factors for cancer and its determinants among Yemen's adult population.

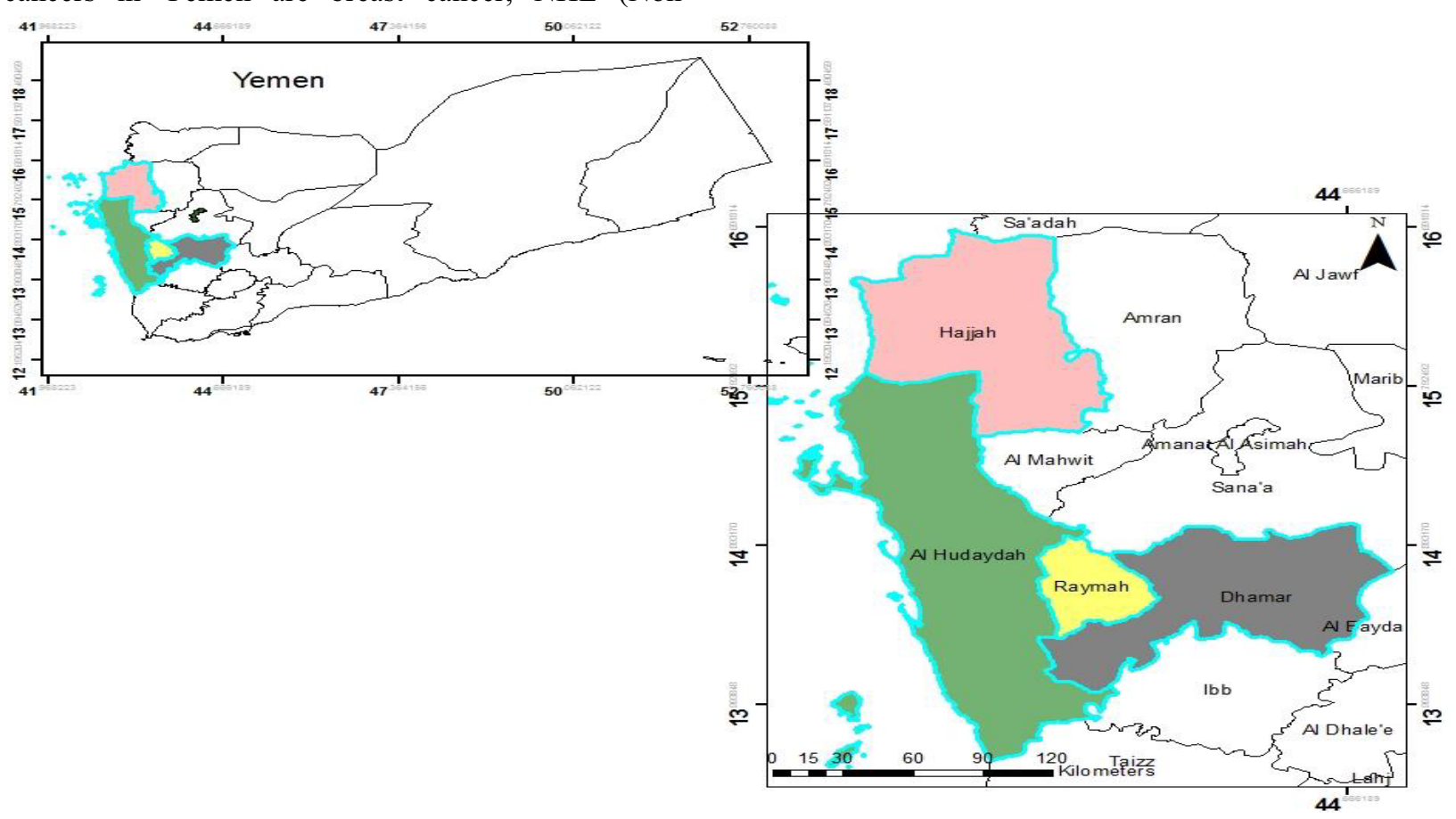

Fig. 1. Sketch Map shows that the four governorates selected for this study 


\section{Materials and Methods}

\subsection{Recruitment of participants}

Yemen is divided geographically into twenty-one governorates. Four governorates (Al Hudaydah, Dhamar, Hajjah, and Raymah (Coastal and mountainous) were selected for this study.

A cross-sectional survey was carried out from 11 January to 25 March 2020, a national random sample of Yemen's adult population aged 18 and up, using a stratified two-stage sampling procedure. The participants to be surveyed were chosen at random from 17 communes and villages, A neighborhood in both an urban and rural area was designated as a cluster. One cluster was chosen at random from each commune in the survey, and one person aged 18 or older from each cluster's household was chosen at random. The total cluster choice was done proportionally to the distribution of the Yemen population with $(50.09 \%)$ males and (49.91\%) females, distributed by (70.1\%) in the rural areas and (29.9\%) in urban areas. The current study received ethical approval based on the current rules for epidemiologic studies, which are compliant with the Helsinki Declaration. It was approved by the Ministry of Health's ethical commission. All subjects gave their consent before answering the survey.

Because of that, 571 adult participants older than 18 years were questioned through a comprehensive questionnaire consisting fundamentally of close-ended questions. To guarantee that the field survey was administered consistently and properly, survey administration training was provided to all field survey interviewers. Prior to embarking on data collection, a pilot study of the first 30 respondents was conducted to assess the ease validity, and reliability of the Arabic version of the questionnaire, also to check the clarity of the questionnaire, establish the reliability, validity, and ease of the questionnaire and to verify data collection methods, particularly to determine the appropriateness of its format, level of difficulty, and length of enough time to complete the questionnaire. The questionnaire took almost 45 to 55 minutes to complete.

Our questionnaire consisted of the following items:

$\begin{array}{ll}\text { - } & \text { Socio-Demographic variables } \\ \text { - } & \text { Tobacco Consumption } \\ \text { - } & \text { Chew Khat and Alcohol consumption } \\ \text { - } & \text { Sutrition Behaviors } \\ \text { - } & \text { Physical Activity } \\ \text { - } & \text { Health Behaviors } \\ \text { - } & \text { Psychological health (Stressors) } \\ \text { - } & \text { Anthropometric Measurements } \\ \text { - } & \text { Cancer Risk Factors }\end{array}$

According to international literature, questions on awareness of several cancer risk factors were included in this survey's questionnaire. Therefore, nine cancerrelated factors were studied.

In this first article for our questionnaire, the Statistical Analysis Strategy was restricted to explore the level of awareness of the above-mentioned cancer-related risk factors and modeling the determinants of knowledge level. Knowledge of cancer risk factors is assessed using data collected from the responses of the participants in this study, so three options were presented for each prospective cancer risk factor::

\section{- $\quad$ Risk factor \\ - Protective factor \\ - I don't know}

The population's knowledge of risk factors for cancer was evaluated by selecting the correct response from these three propositions for each of the presented factors. Each response was given a score of 1 if it was a risk factor or 2 if it was a protective factor or 3 if the participant answered, "I don't know."

\subsection{Data analysis}

All data statistical analyses were conducted using SPSS (IBM Statistical Package ver.20) software. Descriptive statistics for socio-demographic variables (color, residency, age, region of residence, gender, employment status, educational level, marital status, and average family income) and participants' responses to cancer risk factors. A Chi-square test was used to test if there was any relationship between socio-demographic variables and participants' responses. Significance findings $(p<0.05)$ were identified and reported.

\section{Results}

\subsection{Social and Demographic Characteristics of the Study Sample}

The total respondents in the study population sample included 571 people aged older than 18 years. There were 291(50.91\%) males and 280(49.09\%) females, $171(29.9 \%)$ were urban areas, $400(70.1 \%)$ were from rural areas and 486(85.1\%) were white-skinned, $85(14.9 \%)$ were black-skinned. Their ages ranged between 18 and 85 years with mean $=35$ years, median= 31 years, mode $=20$ years, and Std. Deviation $=14.941$. There were $217(38.0 \%)$, Illiterate respondents, with no formal education (cannot read or write), 25(4.4\%) had Quran School, 100(17.5\%) had a primary school, $118(20.7 \%)$ had middle school, 72(12.6\%) had High school, $18(3.2 \%)$ had a diploma, $18(3.2 \%)$ had bachelor, $2(0.4 \%)$ had master, $1(0.2 \%)$ had other. The majority of the respondents $236(41.3 \%)$ were active and 
233(40.8\%) housewives), 355(62.2\%) were low Socioeconomic level and 393(68.8\%) were married Table 1.

Table 1. Sociodemographic Characteristics of Respondents

\begin{tabular}{|c|c|c|}
\hline Variables & $\mathbf{n}$ & Percentage \\
\hline $\begin{array}{l}\text { Residency } \\
\text { Urban } \\
\text { Rural } \\
\end{array}$ & $\begin{array}{l}171 \\
400 \\
\end{array}$ & $\begin{array}{l}29.9 \\
70.1 \\
\end{array}$ \\
\hline $\begin{array}{l}\text { Gender } \\
\text { Male } \\
\text { Female } \\
\end{array}$ & $\begin{array}{l}291 \\
280 \\
\end{array}$ & $\begin{array}{l}50.91 \\
49.09 \\
\end{array}$ \\
\hline $\begin{array}{l}\text { Color } \\
\text { White } \\
\text { Black } \\
\end{array}$ & $\begin{array}{c}486 \\
85 \\
\end{array}$ & $\begin{array}{l}85.1 \\
14.9 \\
\end{array}$ \\
\hline $\begin{array}{c}\text { Educ_level } \\
\text { Illiterate } \\
\text { Literacy School } \\
\text { Quran School } \\
\text { primary school } \\
\text { middle school } \\
\text { High school } \\
\text { Diploma } \\
\text { Bachelor } \\
\text { Master }\end{array}$ & $\begin{array}{c}217 \\
1 \\
25 \\
100 \\
118 \\
72 \\
18 \\
18 \\
2\end{array}$ & $\begin{array}{c}38.0 \\
0.2 \\
4.4 \\
17.5 \\
20.7 \\
12.6 \\
3.2 \\
3.2 \\
0.4\end{array}$ \\
\hline $\begin{array}{c}\text { Marital_Status } \\
\text { Single } \\
\text { Married } \\
\text { Divorced } \\
\text { Widowed }\end{array}$ & $\begin{array}{c}150 \\
393 \\
13 \\
15\end{array}$ & $\begin{array}{c}26.3 \\
68.8 \\
2.3 \\
2.6\end{array}$ \\
\hline $\begin{array}{c}\text { Occupational activity } \\
\text { Active } \\
\text { Retired } \\
\text { unemployed } \\
\text { Housewife }\end{array}$ & $\begin{array}{c}236 \\
20 \\
82 \\
233\end{array}$ & $\begin{array}{c}41.3 \\
3.5 \\
14.4 \\
40.8\end{array}$ \\
\hline $\begin{array}{c}\text { Socioeconomic Level } \\
\text { Low } \\
\text { Average } \\
\text { High }\end{array}$ & $\begin{array}{c}355 \\
201 \\
15\end{array}$ & $\begin{array}{c}62.2 \\
35.2 \\
2.6\end{array}$ \\
\hline
\end{tabular}

\subsection{Level of Knowledge about the Cancer Risk Factors}

Table 2 shows the prevalence of knowledge about cancer causes in the study population sample. Among the 9 risk factors, the most widely known cancercausing factors were tobacco smoking $(87.2 \%)$, physical activity $(83.9 \%)$ as (preventive factor from cancer), alcohol consumption (50.3\%), followed by physical inactivity (45.2\%), and air pollution in cities and indoor smoke $(42.0 \%)$, in general, these results indicated that the level of awareness about the cancer risk factors was low in the study population sample and as a result in the target population. On average, the ceiling of awareness was found to be higher among men than among women $(42.7 \%$ vs $37.3 \%)$ 
Table 2. Prevalence of Correct Knowledge about the Cancer Risk Factors

\begin{tabular}{|c|c|c|c|c|c|}
\hline $\begin{array}{l}\text { Cancer risk } \\
\text { factors }\end{array}$ & Risk factor & $\begin{array}{l}\text { Preventive } \\
\text { factor }\end{array}$ & I don't know & P \% & $\begin{array}{c}\text { Total } \\
\text { respondents for } \\
\text { each Gender }\end{array}$ \\
\hline $\begin{array}{c}\text { Active smoking } \\
\text { Male } \\
\text { Female } \\
\end{array}$ & $\begin{array}{l}268 \\
230 \\
\end{array}$ & $\begin{array}{l}1 \\
3 \\
\end{array}$ & $\begin{array}{l}23 \\
46 \\
\end{array}$ & $87.2 \%$ & $\begin{array}{l}292 \\
279 \\
\end{array}$ \\
\hline $\begin{array}{c}\text { Passive smoking } \\
\text { Male } \\
\text { Female } \\
\end{array}$ & $\begin{array}{r}13 \\
38 \\
\end{array}$ & $\begin{array}{l}1 \\
2 \\
\end{array}$ & $\begin{array}{l}278 \\
239 \\
\end{array}$ & $8.9 \%$ & $\begin{array}{l}292 \\
279 \\
\end{array}$ \\
\hline $\begin{array}{c}\text { Alcohol } \\
\text { consumption } \\
\text { Male } \\
\text { Female } \\
\end{array}$ & $\begin{array}{l}162 \\
125 \\
\end{array}$ & $\begin{array}{l}0 \\
0 \\
\end{array}$ & $\begin{array}{l}130 \\
154 \\
\end{array}$ & $50.3 \%$ & $\begin{array}{l}292 \\
279\end{array}$ \\
\hline $\begin{array}{l}\text { Overexposure to } \\
\text { sunlight } \\
\text { Male } \\
\text { Female } \\
\end{array}$ & $\begin{array}{r}38 \\
33 \\
\end{array}$ & $\begin{array}{l}22 \\
17 \\
\end{array}$ & $\begin{array}{l}232 \\
229 \\
\end{array}$ & $12.4 \%$ & $\begin{array}{r}292 \\
279 \\
\end{array}$ \\
\hline $\begin{array}{c}\text { Lack of fresh } \\
\text { vegetables and } \\
\text { fruits } \\
\text { Male } \\
\text { Female } \\
\end{array}$ & $\begin{array}{l}27 \\
24 \\
\end{array}$ & $\begin{array}{l}3 \\
3 \\
\end{array}$ & $\begin{array}{l}262 \\
252 \\
\end{array}$ & $8.9 \%$ & $\begin{array}{l}292 \\
279 \\
\end{array}$ \\
\hline $\begin{array}{c}\text { Obesity } \\
\text { Male } \\
\text { Female } \\
\end{array}$ & $\begin{array}{l}76 \\
71 \\
\end{array}$ & $\begin{array}{l}0 \\
3 \\
\end{array}$ & $\begin{array}{r}216 \\
205 \\
\end{array}$ & $25.7 \%$ & $\begin{array}{l}292 \\
279 \\
\end{array}$ \\
\hline $\begin{array}{c}\text { Physical inactivity } \\
\text { Male } \\
\text { Female }\end{array}$ & $\begin{array}{c}221 \\
37 \\
\end{array}$ & $\begin{array}{l}7 \\
0 \\
\end{array}$ & $\begin{array}{c}258 \\
48 \\
\end{array}$ & $45.2 \%$ & $\begin{array}{l}292 \\
279\end{array}$ \\
\hline $\begin{array}{c}\text { Physical activity } \\
\text { Male } \\
\text { Female }\end{array}$ & $\begin{array}{l}1 \\
9\end{array}$ & $\begin{array}{l}273 \\
206\end{array}$ & $\begin{array}{l}18 \\
64\end{array}$ & $83.9 \%$ & $\begin{array}{l}292 \\
279\end{array}$ \\
\hline $\begin{array}{l}\text { Air pollution in } \\
\text { cities and indoor } \\
\text { smoke } \\
\text { Male } \\
\text { Female }\end{array}$ & $\begin{array}{l}131 \\
109 \\
\end{array}$ & $\begin{array}{l}0 \\
2 \\
\end{array}$ & $\begin{array}{l}161 \\
168 \\
\end{array}$ & $42.0 \%$ & $\begin{array}{l}292 \\
279 \\
\end{array}$ \\
\hline
\end{tabular}

NOTES: $\mathrm{P} \%=$ proportion (in percentage) of the correct answer (risk factor knowledge)

\subsection{The Determinants of Knowledge about the Cancer Risk Factors}

A significant association was found between the participants' responses and their socio-demographic characteristics where significant differences in average knowledge score were observed depending on the housing category, level of education (Illiterate, Quran school, school education, higher education, university education), area of origin, and family income. Some attitudes were also related to a high level of knowledge score, especially active smoking $(\mathrm{p}=0.001)$, consumption of alcoholic beverages $(p=0.011)$, and physical activity $(\mathrm{p}<0.001)$. However, socioeconomic Level, marital status, color, profession, and monthly Household Income did not show significant influence on the cancer risk factor knowledge score.

\section{Discussion}

Cancer is a preventable and manageable disease. It is important to study the level of knowledge among the population to provide valuable proofs and perspectives towards formulating relevant cancer epidemic prevention plans and strategies. So, a thoughtful, 
comprehensive, and integrated approach is required at the country level, led by the government officials, and with the effective participation of various relevant categories of the community Because data about the level of knowledge in the population are very important for the build and evaluation of cancer epidemic awareness and prevention programs, as far as our know, this is the first research of its kind conducted in Yemen to identify public awareness of risk factors for cancer in the Yemeni population [1].

The vast majority of respondents in our study agreed with the fact that active smoking and consumption of alcoholic beverages increased the risk of getting cancer. This is expected for smoking but it was not expected that the majority of those polled were also aware that consumption of alcoholic beverages was a risk factor for getting cancer. Perhaps this is due to the religious culture of Yemeni society as a Muslim people Hence, Consumption of alcohol is prohibited by religious law. Also, culturally, consumption of alcoholic and smoking are regarded by Arab societies as a "societal stigmatization" and to safeguard their health, people tend not to smoke or drink alcohol. [18].

The results from Some Western studies, where alcohol is commonly used, showed only modest awareness of the public that excessive alcohol intake increased the risk of cancer. On the other side our study showed that, in general, the level of knowledge about Some of the cancer-related risk factors mentioned in this study are not high in the study population; particularly, the participants had poor knowledge about those risk factors that are dependent on relatively deeper knowledge about cancer causation (passive smoking, overexposure to sunlight, lack of fresh vegetables and fruits, obesity, air pollution in cities and indoor smoke, and physical inactivity). Actually, the dietary pattern including sedentary lifestyles is associated with an increase in the risk of cancer [19-20].

Over the past 10 years, the burden of non-communicable diseases, such as cancer, has risen dramatically in the Arab world. [21]. globally, Low vegetable and fruit consumption, alcohol consumption, smoking, and obesity were still the main causes of cancer death. [22]. In Yemen, The low public awareness of the importance of embracing a healthier lifestyle could play a negative role in the increasing incidence of cancer in this country. Indeed, it has been discovered that the risk of getting chronic diseases, such as cancer, decreases as a person adopts a better lifestyle [23-24].

It is perhaps the low public awareness about the relationship between getting frequent sunburn and skin cancer is expected, as skin cancer is uncommon in Yemen and other Arabic countries. Actually, in westerns countries, the incidence of skin cancer continues to increase because of falling ozone levels and lack of skin pigmentation in Caucasian populations [25]. despite that, a UK study showed that the majority of the population was not aware that sun exposure increased the risk of skin cancer and they need to use appropriate sun protection [26].

It should be noted that previous studies conducted in the UK about risk factor cancer showed similar findings and that awareness in the UK was not greater than in Yemen [27-28].

The findings of this study showed a strong relationship between the location of origin and the knowledge score of cancer risk factors. In urban regions, a high level of knowledge was observed and can be explained by the disparity in health facilities between the urban and rural regions and the lack of media access to the rural community. Our search also showed that the higher the respondents' educational level, the more likely they were to be aware of cancer risk factors. It is well known that the level of education is one of the main pillars that determine health, as a low level of education is linked to poor health [17]. The higher the individual's level of education, the greater their awareness of the preventive measures for cancer, and the greater their ability to access more information from different resources, than the less educated individual [29-30]. In the USA a previous study showed that, although Americans lack knowledge about the major risk factors for common cancers, the majority were among those with the lowest educational level [31]. Actually, the higher the level of education, the lower the mortality rate from cancer. It has been suggested, therefore, that identifying groups at high risk of death from cancer by the level of education is useful in targeting interventions and tackling cancer disparities [32].

Our study has two limitations that should be mentioned. Firstly, the sample has been selected because of convenience and taken from only four areas in Yemen. Hence it might not be applicable to the whole community. A larger national study with a more representative sample size is required. Secondly, some existing special conditions (war) in Yemen, may lead to an overestimate or versa of the level of knowledge and as a result, this may limit the generalizability of the results obtained. In other words, these results may not reflect the level of awareness of the Yemeni general public about cancer risk factors. As far as we know, this is the first research of its kind that evaluates the level of awareness for some cancer-protective or risk factors in Yemen. Based only on established risk or protective cancer factors was calculate the score. This score may aid in the development of a strategy for raising public knowledge of cancer risk factors in Yemen, which could be beneficial in the development of public health campaigns to prevent cancer. 


\section{Conclusion}

In conclusion, similar to studies in other countries in the world, the findings of this survey suggest that public awareness and knowledge of cancer risk factors is insufficient in Yemen. The findings showed that the higher the educational level, the more likely population are to be aware of risk factors for cancer, the level of knowledge was influenced by socio-demographic factors. The study suggests that both professional efforts and public education in improving awareness and knowledge of cancer risk factors are urgently needed. It appears that the study is the first of its kind in Yemen to evaluate the public cancer risk factors knowledge. As the incidence of cancer in Yemen increases, further studies with larger sample sizes covering the entire population in Yemen are highly recommended, plans and plans and strategies to increase public awareness for risk factors for cancer for all common types of cancer are needed. The use of mass media, brochures, school visits, and posters in hospitals and primary care health facilities can all help to raise public awareness of cancer risk factors.

\section{Acknowledgments}

The authors would like to express their gratitude to all individuals, who agreed to participate in the study.

\section{Reference}

1. Feizi, A. Kazemnejad, G. Babaee, Z. Parsayekta, Z. Monjamed, Public awareness of risk factors for cancer and its determinants in an Iranian population, APJPH, 22(1),76-88(2010)

2. M. Garcia, A. Jemal, E. Ward, M. Center, Y. Hao, RL. Siegel, MJ. Thun, Global Cancer Facts \&Figures. GA: American Cancer Society Atlanta, (2007).

3. K. Poudel, N. Sumi, Knowledge about risk factors for Cancer among adults in Nepal, $K$ L S, 126-136(2018).

4. M. Al-Azri, I. Al-Hamedi, H. Al-Awisi, M. AlHinai, R. Davidson, Public awareness of warning signs and symptoms of cancer in Oman: a community-based survey of adults, A P J C P, 16(7), 2731-2737(2015).

5. K. Ravichandran, G. Mohamed, N.A. Al Hamdan, Public knowledge on cancer and its determinants among Saudis in the Riyadh Region of Saudi Arabia, A P J C P, 11, 1175-80, November
(2015), http://www.biomedcentral.com/1741$7015 / 12 / 3$

6. A. Feizi, A. Kazemnejad, M. Hosseini, Z. Parsayekta, J. Jamali, Assessing Awareness Level about Warning Signs of Cancer and its Determinants in an Iranian General Population, $\mathrm{J} \mathrm{H}$ P N, 6, 656- 9, November (2015). http://www.ncbi.nlm.nih.gov/pmc/articles/PMC3 259730/pdf/jhpn0029-0656.pdf

7. S. C. Sanderson, J. Waller, M. J. Jarvis, S. E. Humphries, J. Wardle, Awareness of lifestyle risk factors for cancer and heart disease among adults in the UK, 74(2), 221-227(2009).

8. J. L. Loo, Y. K. Ang, H. S. Yim, Development and validation of a cancer awareness questionnaire for Malaysian undergraduate students of Chinese ethnicity, $A P J C P, 14(1)$, 565-570(2013).

9. Loo, J. L., Woo, W. Y., Chin, M. W., Yam, H. R., Ang, Y. K., \& Yim, H. S. Cancer awareness of a sample of Malaysian undergraduate students, A J C P, 1(1), 9-13(2013).

10. M. Al-Azri, K. Al-Rasbi, M. Al-Hinai, R. Davidson, A. Al-Maniri, Awareness of risk factors for cancer among Omani adults-a community based study, APJCP, 15(13), 5401-5406(2014).

11. S. Qassim, Y. Al-Hariri, S. Shanableh, A. Farajallah, F. Boura, Awareness Level of Cancer Warning Signs and its Determinants among University Students in UAE, JPSR, 10(3), 514-517 (2018).

12. W H O, Obesity: preventing and managing the global epidemic(2000).

13. A. Jemal, R. Siegel, E. Ward, T. Murray, J. Xu, M. J. Thun, Cancer Statistics, 2007, CA Cancer J Clin, 57, 43-66(2007).

14. A. L. Afif, A. M. Algharati, G. A. Hamid, A. W. Al-Nehmi, A. Shamlan, PATTERN OF CANCER IN YEMEN: FIRST RESULT FROM THE NATIONAL ONCOLOGY CENTER, SANA'A, (2007).

15. T. Vandenberg, N. Nagi, B. Garcia, C. Kirk, J. Gilchrist, S. Poirier, M. Robinsong, The National Oncology Program: a Yemeni-Canadian partnership. Hematology/oncology and stem cell therapy, 2(1), 294-298(2009).

16. M. Al-Moundhri, B. Al-Bahrani, I. Pervez, S. S. Ganguly, V. Nirmala, A. Al-Madhani, C. Grant, The outcome of treatment of breast cancer 
in a developing country-Oman. The Breast, 13(2), 139-145(2004).

17. A. E. Simon, D. Juszczyk, N. Smyth, E. Power, S. Hiom, M. D. Peake, J. Wardle, Knowledge of lung cancer symptoms and risk factors in the UK: development of a measure and results from a population-based survey. Thorax, 67(5), 426-432(2012).

18. H. G. Ahmed, Survey on knowledge and attitudes related to the relation between tobacco, alcohol abuse and cancer in the northern state of Sudan, APJC, 14(4), 2483-2486(2013).

19. C. Redeker, J. Wardle, D. Wilder, S. Hiom, A. Miles, The launch of Cancer Research UK's 'Reduce the Risk'campaign: baseline measurements of public awareness of cancer risk factors in 2004. EJc, 45(5), 827-836(2009).

20. J. Wardle, J. Waller, N. Brunswick, M. J. Jarvis, Awareness of risk factors for cancer among British adults, Public health, 115(3), 173174(2001).

21. C. Falzon, A. Chalabaev, L. Schuft, C. Brizzi, M. Ganga, Beliefs about physical activity in sedentary cancer patients: an in-depth interview study in France, APJCP, 13(12), 60336038(2012).

22. A. S. Yusof, Z. M. Isa, S. A .Shah, Dietary patterns and risk of colorectal cancer: a systematic review of cohort studies (2000-2011), APJCP, 13(9), 4713-4717(2012).

23. H. F. A. Rahim, A. Sibai, Y. Khader, N. Hwalla, I. Fadhil, H. Alsiyabi, A. Husseini, Noncommunicable diseases in the Arab world. The Lancet, 383(9914), 356-367(2014).

24. A. M. Ryan, S. Cushen, H. Schellekens, E. N. Bhuachalla, L. Burns, U. Kenny, D. G. Power, Poor awareness of risk factors for cancer in Irish adults: results of a large survey and review of the literature. The oncologist, 20(4), 372(2015).

25. X. O. Liu, Y. B. Huang, Y. Gao, C. Chen, Y. Yan, H. J. Dai, K. X. Chen, Association between dietary factors and breast cancer risk among Chinese females: systematic review and metaanalysis, APJCP, 15(3), 1291-1298(2014).

26. R. F. Tayyem, I. N. Shehadeh, S. S. AbuMweis, H. A. Bawadi, S. S. Hammad, K. E. Bani-Hani, M. M. Alnusai, Physical inactivity, water intake and constipation as risk factors for colorectal cancer among adults in Jordan, APJCP, 14(9), 5207-5212(2013).
27. M. Tarstedt, O. Larkö, L. Molin, A. M. Wennberg, Increasing number of skin cancer cases--also among the younger. Lakartidningen, 102(26-27), 19721975(2005).

28. A. Miles, J. Waller, S. Hiom, D. Swanston, SunSmart? Skin cancer knowledge and preventive behaviour in a British population representative sample, HER, 20(5), 579-585(2005).

29. T. Faresjö, M. Rahmqvist, Educational level is a crucial factor for good perceived health in the local community, Sjoph, 38(6), 605-610(2010). 30. A. A. Norlaili, M. A. Fatihah, N. F. N. Daliana, D. Maznah, Breast cancer awareness of rural women in Malaysia: is it the same as in the cities?, APJCP, 14(12), 7161-7164(2013).

31. R. A. Breslow, J. D. Sorkin, C. M. Frey, L. G. Kessler, Americans' knowledge of cancer risk and survival. Preventive Medicine, 26(2), 170177(1997).

32. J. D. Albano, E. Ward, A. Jemal, R. Anderson, V. E. Cokkinides, T. Murray, M. J. Thun, Cancer mortality in the United States by education level and race, JNCl, 99(18), 1384-1394(2007). 